\title{
What could be learned from the utilization of Design for Environment within manufacturing companies?
}

\author{
Mattias Lindahl, Olof Hjelm, Erik Sundin and Leif Thuresson
}

\section{Linköping University Post Print}

\section{Tweet}

N.B.: When citing this work, cite the original article.

Original Publication:

Mattias Lindahl, Olof Hjelm, Erik Sundin and Leif Thuresson, What could be learned from the utilization of Design for Environment within manufacturing companies?, 2005, Fourth International Symposium on Environmentally Conscious Design and Inverse Manufacturing, 2005: Eco Design 2005, 232-237. ISBN: 1-4244-0081-3

http://dx.doi.org/10.1109/ECODIM.2005.1619208

From EcoDesign 2005: 4th International Symposium on Environmentally Conscious Design and Inverse Manufacturing, December 12-14, 2005 in Tokyo, Japan

Postprint available at: Linköping University Electronic Press

http://urn.kb.se/resolve?urn=urn:nbn:se:liu:diva-36427 


\title{
What could be learned from the utilization of Design for Environment within manufacturing companies?
}

\author{
Mattias Lindahl ${ }^{1}$, Olof Hjelm ${ }^{1}$, Erik Sundin ${ }^{2}$ \& Leif Thuresson ${ }^{1}$ \\ ${ }^{1}$ Environmental Technology and Management, Department of Mechanical Engineering \\ ${ }^{2}$ Production System, Department of Mechanical Engineering \\ Linköping University, Sweden \\ Mattias.Lindahl@ikp.liu.se
}

\begin{abstract}
This paper describes experiences from several years of DfE studies at different manufacturing companies, as well as their strategies for approaching $D f E$.

The general experience from the authors is that in order to make DfE truly utilized, it must become a "living part" of the company. To reach this point, it is important to obtain a strong commitment not only from the manufacturing company's management, but also from other DfE stakeholders throughout the company, at both the strategic and operational levels.

DfE initiatives must be considered as a strategic issue and an investment in increased competitiveness.

When summarizing all the experiences presented in this paper, a conclusion is that manufacturing companies often have a need for a general model that focuses on how to make "DfE thinking" a natural part of the company's way of doing business.
\end{abstract}

Key words: Design for Environment, DFE, Utilization, Environmental Management System, EMS.

\section{Introduction}

During the last decade, environmental concerns within society have increased and become an increasingly important issue for companies [1]. Since up to $90 \%$ of a product's environmental impact is determined during the design process [2], there have been an increasing number of arguments for the need of Design for Environment (DfE). Bakker [3] defines DfE as "the development of products by applying environmental criteria aimed at the reduction of the environmental impacts along the stages of the product life cycle".

In parallel, there has been a trend towards the rapid development of methods and tools to employ in the area of product development. The result is a considerable number of DfE methods and tools as seen in, for example, Simon et al. [4] and Wrisberg et al. [5].
Potential DfE methods and tools fall into a wide range of categories, from relatively simple checklists or general guidelines to more complex software-based decisionmaking methods [5]. Several governments, e.g. Sweden and Holland, have in various ways tried to support and encourage companies to incorporate DfE within their daily business $[6,7]$.

According to Mathieux et al. [8], extensive research on DfE, mainly in the areas of strategy, methodology, and tools, has been carried out by research organizations and industrial companies. For example, Bhamra et al. [9] and Ritzén [10], among others, have argued that environmental aspects need to be integrated into product development as early as possible, and not handled independently.

A great amount of literature has been published concerning how to perform $\boldsymbol{D} \boldsymbol{f E}$, for example Brezet and Hemel [11], Gertsakis et al. [12], Lewis and Gertsakis [13] and Ryding et al. [14]. The ISO has developed a technical report within the ISO 14000 framework on how to integrate environmental aspects into product development [15]. Despite the literature and technical report mentioned above, McAloone et al. [16] have stated that little focus has been given to how DfE should be implemented in industry - in particular beyond a company's environmental department and into the product development, marketing and sales departments, and in fact throughout the whole business [16].

There seems to be a gap between how to perform DfE and its actual applications, research and validation of its current use DfE within industry. Despite the fact that many DfE methods and tools have been developed, only a few researchers, for example Norell [17], Araujo et al. [18], Cantamessa [19], Beskow [20], Ritzén [10], Janhager et al. [21] and López-Mesa [22], have conducted research concerning the use of methods and tools, and especially on the use of DfE methods and tools within industry.

The industrial utilization and importance of DfE has still, after more than decade, not yet become prevalent. When DfE methods and tools are used, for example, they 
are often not integrated into the product development process. This is a point highlighted by Baumann et al. [23], Ernzer and Birkhofer [24] and Tukker et al. [25]. NUTEK, the Swedish Business Development Agency [26], had a similar conclusion in its final report on a threeyear long DfE program. According to the report, some large multinational companies (particularly in the fields of electrical and electronic goods, motor vehicles and packaging) are addressing the issue in a rather comprehensive way, and the study concludes that DfE plays a small role in many companies (particularly small and medium-sized enterprises).

\section{Objectives}

The objective for this paper is to highlight some experiences and "lessons learned" from utilization of DfE within manufacturing companies. The overall aim is to further improve utilization as well as implementation of DfE in companies.

\section{Research method}

The authors of this paper have extensive experience from a large number of DfE (and EMS ${ }^{1}$ ) projects within Swedish manufacturing companies. This paper is based on a literature review of the utilization of DfE and DfEmethods and tools within companies, as well as several studies and surveys performed by the authors and the students they have supervised in master's degree and smaller course projects, see e.g. [26-34]. Both the types of companies covered in these projects and the types of products vary.

\section{Experience of DfE}

The authors' experience is that there is no single answer of how to best perform DfE in manufacturing companies, since so much depends on the manufacturing company context, e.g. what kind of product it manufactures.

\subsection{Do manufacturers need DfE?}

The need for DfE depends on the different stakeholders' influence on the manufacturer, stakeholders who can vary depending on e.g. the product, company, market and point in time. For some companies, it is of vital importance to work with DfE in order to be able to sell, since their customers demand e.g. increasingly environmentally conscious products. For other companies, the major benefits from their DfE work comes

\footnotetext{
${ }^{1}$ Standardized Environmental Management Systems (EMS)
}

from internal cost savings, e.g. from more efficient material and energy use or from less costly service.

When identifying stakeholders, it is important to consider that different stakeholders within the company, such as different departments and groups (designers, management, etc.), may have different and sometimes contradictory needs, something that must not be forgotten in obtaining effective and efficient DfE management.

\subsection{Do manufacturers have different approaches to DfE?}

Manufactures have different ways of approaching DfE; for example, some just test it because of curiosity and to see if they can gain anything. Others introduce DfE based on various stakeholders' requirements. Based on the authors' projects and those of others, several examples of DfE approaches have been identified and are presented below.

The pilot project approach - This is an often used approach for companies that are e.g. curious about DfE and want to test and verify the concept. The experience is that, since environmental issues are usually not treated as strategic issues, they tend to be unfairly treated and not prioritized. The literature is full of examples of pilot DfE projects on the corporate level, but there are few examples of thier integration into product development [35].

The incremental approach - Changes late in the product development process translate into small gains at high cost. The authors have seen many companies that have started DfE projects on existing products with small opportunities for change; the benefits, not surprisingly, has been negligible and often involve costly environmental improvements, a result which is not surprising when considering Ullman's [36] design paradox.

The concept approach - Many manufacturing companies, especially those in industries that have a great deal of pressure from external stakeholders, are developing environmental concepts to complement their other products in e.g. the automotive industry, cellular phone industry, etc. [37]. These concepts are often expensive to develop, and there is seldom a market for them since they often have a much higher price than ordinary products.

The EMS integration approach - There are manufacturers that are attempting to integrate DfE into EMS operations, see e.g. [38]. This approach to DfE has great potential, since it becomes integrated in the manufacturer's environmental work and could stimulate continuous work with DfE issues.

The product development process integration approach - With this approach, environmental issues are integrated into the product development process. DfE issues are implemented in the same manner as, for 
example, quality issues. One way to do this is to integrate environmental issues into other design methods and tools, see e.g. [32].

\subsection{How can DfE become a natural part of a company's activities?}

In many companies, environmental champions have been important actors and catalysts in the introduction of DfE (see also [35]). However, the authors' experience and that of others, e.g. Simon et al. [4], is that environmental champions are not enough to make DfE a more sustainable, natural and frequent activity within a company. What is needed is activity at two levels: the strategic, to promote the issue within the entire organization, and the operational, to put the good intentions into practice in product development. This is also supported by e.g. Ritzén and Beskow [39] and Lenox et al. [40], who states that DfE activities are often characterized by a disconnection between activities on the corporate level and those on the product development level.

The strategic level is often more closely related to a company's organization of its processes, whereas the operational level is more related to a company's products. The relative importance and focus may differ between major and small companies; still, both the strategic and operational levels must be coordinated in order to introduce fruitful DfE - and in the long term contribute to a prosperous business.

However, the authors' experience is that DfE in its most basic form is a way of thinking and acting that could be seen as an ongoing learning process. Multidisciplinary communication, along with education and continuous follow-up, are important factors in this learning process.

Multidisciplinary communication - Different stakeholders tend to express their goals and requirements in different ways. Holistic, multidisciplinary communication contributes to an increased understanding of different stakeholders' views and understanding of DfE goals and how to reach them. Nevertheless, it seems to be preferable if requirements are translated to comply with the receiver's way of expressing requirements. For example, requirements from the EMS system about reduction of carbon dioxide should be translated and expressed to designers as e.g. decreased fuel consumption by 0.1 liter per kilometer.

Education - One way to gain awareness for DfE is through education. According to Beskow [20], education should begin with general information about what context the DfE method or tool should be used in, why it should be used, and also the background behind the methodology. Following this, more specific information about the DfE method or tool and how to use it should be presented. The authors' experience is in line with the above, since designers tend to prefer getting an education that on an overarching level encompasses general DfE issues like life cycle perspective and environmental impact. Before embarking on detailed education, however, they tend to want to test and utilize their newly attained knowledge in order to, for example, see what they do not understand and have questions about. This implies that the education must be quite customized.

Reflection and follow-up - Another way to gain awareness about DfE is through continuous reflection of how DfE methods and tools are utilized and how they can be used to contribute to thier own work. This, in combination with education of the staff, is necessary in order to maintain the company's competitiveness [20]. Studies [27, 28, 30, 31] have shown that the experience among the designers is that they in general have limited time for reflection on their daily work due to their everyday work activities, implying that time available for reflection on the usefulness of methods and tools is limited. Reflection can also take other forms; the more formal follow-up of utilized DfE methods and tools is one example. At the same time, three out of ten designers stated that there was no follow-up of unsuccessful method and tool use [31]. The studies show that the low degree of follow-up is independent of the size of the company [27, $28,30,31]$. The research studies show a generally low degree of follow-up of designers' methods and tools.

Finally, it is the authors' general experience that to get DfE to become a natural part of a company's activities, DfE must, in the long term, have a direct or indirect impact on making a company's business more profitable. However, in what way it is more profitable is another question, as it could be related to internal or external profitability. Internal profitability is mainly related to cost savings, while external profitability concerns such things as customer benefits that could render a higher market price.

\subsection{How important is the need for DfE methods and tools?}

Research by Lindahl [41] indicates no general need for additional DfE methods and tools; this is also addressed by e.g. Ernzer et al. [42].

According to Beskow [20], DfE methods and tools can facilitate learning and collaboration, activities of high importance when integrating environmental aspects into product development. Even so, the authors' general experience is that there has been overconfidence in the utilization of DfE methods and tools and their ability to introduce sustainable DfE into manufacturers' product development. There are several examples in the literature of e.g. government-funded DfE method and tool focused projects, e.g. DfE (demonstration) projects that have tried to introduce DfE into companies, but these have rarely led 
to the use of DfE in ordinary product development [25, 43]. In general the only result has been a redesign of specific products. When those projects have been followed up, the general experience is that the DfE work has declined or died after the project's end. However, this is not a surprise; as earlier mentioned, DfE is more a way of thinking and acting than a specific DfE method or tool. Thus, simply choosing, applying and focusing on a certain DfE method or tool is not an automatic way to introduce sustainable DfE into product development [41, 44].

Finally, research by e.g. Lindahl [41] indicates that today's DfE method and tool selection is unstructured and often dependent on a DfE method or tool's popularity at the moment rather than on a real analysis of the need. Sometimes, a specific tool is selected on the basis that a major customer or competitor is using it. Of course, the latter can sometimes be relevant if the tool generates an outcome that can be compared with the competitor's result. The implication of this unstructured selection and lack of DfE method and tool requirements implies that it is hard to evaluate the gains from the use of the method or tool, since there are no values to compare the result with.

\subsection{How important is the connection between DfE and EMS?}

Since environmental impacts are intimately connected to flows of materials and energy, and the most important flows, at least for manufacturing companies, are closely linked to products (see e.g. Ayres [45] and Berkhout [46]), it seems urgent for management systems to encompass products and product development. Consequently, it appears vital to investigate the connection between EMS and DfE [47]. In addition, many DfE initiatives have a pilot project character [48, 49]. This is seen as a problem, since companies tend to return to 'business as usual' after completing such DfE projects, i.e. the long-lasting strategic and organizational changes and the accompanying product improvements are missing. Brezet and Rocha [49] state that "It is recognized that eco-design activities will be limited if they are not integrated into strategic management and the daily operations of companies in a dynamic process of continuous environmental performance improvements" (cf. [50]).

Standardized EMS have the potential to remove this barrier to DfE implementation by establishing an organizational structure where procedures for the inclusion of environmental criteria are facilitated and made permanent. Ammenberg and Sundin [39] suggest integrating DfE and EMS through a PDCA cycle. This concerns how to integrate DfE and EMS, and is described in more detail by Ammenberg and Sundin [38, 47].

\section{Conclusions}

The authors' general experience from working with the manufacturing companies is that if $\mathrm{DfE}$ is to see increasing utilization, it must become a "living part" of the company. To reach this point, it is important to obtain a strong commitment not only from company management, but also from the different DfE stakeholders within the entire company, i.e. those at both the strategic and operational levels. In other words, all concerned must work in the same direction.

DfE work must be considered as a strategic issue and an investment in increased competitiveness.

When summarizing all the experiences presented in this paper, the conclusion is that there is a need for a general framework that focuses on how to make DfE thinking a natural part of the company's way of doing business .

\section{References}

[1] DeSimone, L. and F. Popoff, Eco-Efficiency, The Business Link to Sustainable Development, Cambridge, MA: MIT Press, 292, (1997).

[2] Keoleian, G.A. and D. Menerey, Sustainable Development by Design: Review of Life Cycle Design and Related Approaches, Journal of the Air and Waste Management Association, 44: p. 664-668, (1994).

[3] Bakker, C., Environmental Information for Industrial Designers, PhD-Thesis, PhD-Thesis, Delft, Holland: Delft University of Technology, (1995).

[4] Simon, M., S. Evans, T.C. McAloone, A. Sweatman, T. Bhamra, and S. Poole, Ecodesign Navigator - A Key resource in the Drive towards Environmentally Efficient Product Design, Manchester, UK: Manchester Metropolitan University, Cranfield University \& EPSRC, (1998).

[5] Wrisberg, N., H.A. Udo de Haes, U. Triebswetter, P. Eder, and R. Clift, eds., Analytical Tools for Environmental Design and Management in a Systems Perspective. Kluwer Academic Publishers: Dordrecht, (2000).

[6] Nutek, Sustainable products - new business through Design for Environment, Stockholm, Sweden: Swedish Business Development Agency, (2003).

[7] Rubik, F., Scholl, G., Integrated Product Policy (IPP) in Europe-a development model and some impressions $<\sup >1</$ sup $>$, Journal of Cleaner Production, 10(5): p. 507-515, (2002).

[8] Mathieux, F., G. Rebitzer, S. Ferrendier, M. Simon, and D. Froelich, Ecodesign in the European Electr(on)ics Industry - An analysis of the current practices based on cases studies, The Journal of Sustainable Product Design, 1(4): p. pp. 233-245, (2001).

[9] Bhamra, T.A., S. Evans, T.C. McAloone, M. Simon, S. Poole, and A. Sweatman, Integrating environmental decisions into the product development process. I - The early stages, in Proceedings. EcoDesign '99: First International Symposium on Environmentally Conscious Design and Inverse Manufacturing: IEEE Computer Soc, (1999). 
[10] Ritzén, S., Integrating environmental aspects into product development - Proactive measures, Ph.D. thesis, Integrated Product Development Division, Dept. of Machine Design, Stockholm, Sweden: Royal Institute of Technology, (2000).

[11] Brezet, H. and C.v. Hemel, eds., Ecodesign - A Promising Approach to Sustainable Production and Consumption. Delft University of Technology: Delft, Netherlands, (1997).

[12] Gertsakis, J., H. Lewis, and C. Ryan, A Guide to EcoReDesign - Improving the Environmental Performance of Manufactured Products, Melbourne, Australia: Centre for Design at RMIT, (1997).

[13] Lewis, H., J. Gertsakis, T. Grant, N. Morelli, and A. Sweatman, Design + Environment - a global guide to designing greener goods, Sheffield, UK: Greenleaf Publishing Limited, (2001).

[14] Ryding, S.-O., Miljöanpassad produktutveckling, Stockholm, Sweden: Industrilitteratur AB, (1995).

[15] ISO 14 062, Environmental management - Integrating environmental aspects into product design and development, International Organization for Standardization: Geneva, Switzerland, p. 24, (2002).

[16] McAloone, T.C., N. Bey, C. Boks, M. Ernzer, and W. Wimmer, Towards the actual implementation of ecodesign in industry - the "haves" and "needs" viewed by the European ecodesign community, in Going Green - CARE INNOVATION 2002, Fourth International Symposium, Vienna, Austria, (2002).

[17] Norell, M., The use of DfA, FMEA and QfD as tools for Concurrent Engineering in Product Development Processes, in 9th International Conference on Engineering Design - ICED 93, Netherlands Congress Centre, The Hague, Netherlands: Heurista, (1993).

[18] Araujo, C.S., H. Benedetto-Neto, A.C. Campello, F. Segre, and I.C. Wright, The Utilization of Product Development Methods: A Survey of UK Industry, Journal of Engineering Design, 7(3): p. pp 265-277, (1996).

[19] Cantamessa, M., Design Best Practices, Capabilities and Performance, Journal of Engineering Design, 10(4): p. 305328, (1999).

[20] Beskow, C., Towards a Higher Efficiency - Studies of Changes in Industrial Product Development, Doctoral Thesis, Integrated Product Development, Department of Machine Design, Stockholm, Sweden: Royal Institute of Technology, (2000).

[21] Janhager, J., S. Persson, and A. Warell, Survey on Product Development Methods, Design Competencies and Communication in Swedish Industry, in TMCE 02, Wuhan, China, (2002).

[22] López-Mesa, B., The use and suitability of design methods in practice - Considerations of problem-solving characteristics and the context of design, Doctoral Thesis, Department of Applied Physics and Mechanical Engineering, Division of Computer Aided Design, Luleå, Sweden: Luleå University of Technology, (2004).

[23] Baumann, H., F. Boons, and A. Bragd, Mapping the green product development field: engineering, policy and business perspectives, Journal of Cleaner Production, 10(5): p. 409-425, (2002).

[24] Ernzer, M. and H. Birkhofer, Selecting Methods for Life Cycle Design Based on the Needs of a Company, in
International Design Conference - Design 2002, Dubrovnik, Croatia, (2002).

[25] Tukker, A., E. Haag, and P. Eder, Eco-design: European state of the art - Part I: Comparative Analysis and Conclusions - An ESTO project report, Brussels, Luxembourg: European Commission - Joint Research Centre Institute for Prospective Technological Studies, 60, (2000).

[26] Nutek, Metodik för Miljöanpassad produktutveckling i små och medelstora företag - slutrapport från ett treårigt NUTEK-program (Methodology for Design for Environment in small and medium sized enterprises - Final report from a three-year Nutek-program) - In Swedish, Stockholm, Sweden: Nutek, (2002)

[27] Lindahl, M. and A.-M. Åkermark, Experience of and requirements on methods for product development - An interview survey at a major Swedish vehicle company: Linköping, Sweden, (2004).

[28] Lindahl, M., Engineering designers' experience of design for environment methods and tools - Requirement definitions from an interview study, Journal of Cleaner Production, Elsevier, In press, (2005).

[29] Jilderin, J. and H. Omberg, Usability and demands on design engineering tools and methods utilized in Small and Medium Sized Enterprises - A different approach to understand the reasons behind the low utilization of $D f E$ methods and tools, Linköping, Sweden: University of Linköping, (2004).

[30] Lindahl, M., L. Skoglund, J. Svensson, and R. Karlsson, Use and perception of Design for Environment (DfE) in Small and Medium Sized Enterprises in Sweden, in EcoDesign 2003: 3rd International Symposium on Environmentally Conscious Design and Inverse Manufacturing, Tokyo, Japan: Union of EcoDesigners (Association of EcoDesign Societies, Japan), (2003).

[31] Lindahl, M., User Requirements for Design for Environment methods and tools - Based on a web-based questionnaire survey, Journal of Sustainable Product Design, Submitted for publication, (2004).

[32] Persson, A. and C. Sandström, Scania-anpassat verktyg för värdering av produkters miljöprestanda, Master thesis, Dept. of Mechanical Engineering, Linköping, Sweden: Linköping University, (2004).

[33] Jonsson, C. and M. Öberg, Performance and Comparision of LCA and EEA for Autoliv Electronics AB in Motala, Sweden, Master, Environmental Technology and Management, Department of Mechanical Engineering, Linköping, Sweden: Linköping Institute of Technology, (2004).

[34] Jaensson, E., Miljöeffektsanalys av elektronikprodukter Flextronics-anpassat verktyg och arbetssätt - Flextronics $A B$ (in Swedish), Master thesis, Dept. of Mechanical Engineering, Linköping, Sweden: Linköping University, (2004).

[35] Ehrenfeld, J.R. and M.J. Lenox, The Development and Implementation of DfE Programmes, The Journal of Sustainable Product Design., (1): p. 17-27, (1997).

[36] Ullman, D., G., The Mechanical Design Process, Third Edition ed, New York, USA: McGraw-Hill Higher Education, 415, (2002). 
[37] Berg, E. and E. Lindgren, Environmental Assessment of Two Door concepts for Trucks at Scania CV AB (in Swedish), Master thesis, Dept. of Mechanical Engineering, Linköping, Sweden: Linköping University, (2001).

[38] Ammenberg, J. and E. Sundin, Products in environmental management systems: the role of auditors, Journal of Cleaner Production, (2003).

[39] Ritzén, S. and C. Beskow, Actions for integrating environmental aspects into product development, The Journal of Sustainable Product Design, Kluwer Academic Publishers, 1(2): p. 91-102, (2001).

[40] Lenox, M., B. Jordan, and J.R. Ehrenfeld, The Diffusion of DfE: A Survey of Current Practice, in Proceedings from the IEEE Symposium on Electronics and the Environment: IEEE, (1996).

[41] Lindahl, M., Engineering Designers' Requirements on Design for Environment Methods and Tools, Doctoral thesis, Industrial Engineering and Management, Stockholm, Sweden: KTH, (2005).

[42] Ernzer, M., C. Oberender, and H. Birkhofer, DfE for companies - an easy-to-use individaulized method-mix for $D f E$, in Proceedings from the 13th International Conference of Engineering Design, Glasgow, UK, (2001).

[43] Hillary, R., ed. Small and Medium-Sized Enterprises and the Environment. Greenleaf Publishing Limited: Sheffield, UK, (2000).

[44] Ritzén, S. and M. Lindahl, Selection and implementation key activities to successful use of EcoDesign tools, in Proceedings EcoDesign 2001: Second International Symposium on Environmentally Conscious Design and Inverse Manufacturing, Tokyo, Japan, (2001).

[45] Ayres, R.U., Industrial Metabolism: Theory and Policy, in Industrial Metabolism - Restructuring for Sustainable Development, R.U. Ayres and U.E. Simonis, Editors, United Nations University: Tokyo, Japan. p. 3-20, (1994).

[46] Berkhout, F., Aggregate Resource Efficiency. Are Radical Improvements Impossible?, in IManaging a Material World. Perspectives in Industrial Ecology, P. Vellinga, F. Berkhout, and J. Gupta, Editors, Kluwer Academic Publishers. p. 165-189, (1998).

[47] Ammenberg, J. and E. Sundin, Products in Environmental Management Systems: Drivers, Barriers and Experiences, Journal of Cleaner Production, 13(4): p. pp 405-415, (2005).

[48] Charter, M. and I. Belmane, Integrated Product Policy (IPP) and Eco-Product Development (EPD), The Journal of Sustainable Product Design, (1999).

[49] Brezet, H. and C. Rocha, Towards a Model for ProductOriented Environmental Man-agement Systems, in In Sustainable Solutions, M. Charter and U. Tischner, Editors, Greenleaf Publishing: Sheffield, UK, (2001).

[50] BATE (Business and the environment), Lucent Technologies Applies ISO 14001 to design for environment functions, ISO 14001 Update 6.2, (2000). 